УДК 343.1

12.00.00 Юридические науки

ПОДГОТОВКА ПРОКУРОРА К

РЕАЛИЗАЦИИ ФУНКЦИИ УСТАНОВЛЕНИЯ ОБЪЕКТИВНОЙ ИСТИНЫ В СУДЕБНОМ РАЗБИРАТЕЛЬСТВЕ ПО УГОЛОВНЫМ ДЕЛАМ

Тушев Александр Александрович заведующий кафедрой уголовного процесса, доктор юридических наук, профессор

Кудин Федор Милентьевич

профессор кафедры уголовного процесса, доктор юридических наук

Тхакушинов Магомет Асланчериевич профессор кафедры уголовного процесса, доктор юридических наук

Теучеж Асфар Асланбиевич аспирант очного отделения кафедры уголовного процесса

ФГБОУ ВО «Кубанский государственный аграрный университет имени И.Т. Трубилина», Краснодар, Россия

В настоящей работе авторами рассматривается актуальный для правоприменительной практики вопрос о подготовке прокурора к реализации уголовно-процессуальной функции установления объективной истины в судебном разбирательстве по уголовному делу. На основе указаний Генерального прокурора РФ, прокурора Краснодарского края, проведенного анкетирования действующих сотрудников органов прокуратуры РФ, мнений ученых-процессуалистов, собственных суждений авторов обосновывается вывод о реализации прокурором указанной функции, и даются практические рекомендации по подготовке ее осуществления. Проводится комплексный анализ уголовно-процессуальных полномочий прокурора, позволяющих ему эффективно добиваться установления объективной истины по уголовному делу

Ключевые слова: ПРОКУРОР, УГОЛОВНОПРОЦЕССУАЛЬНАЯ ФУНКЦИЯ, ОБЪЕКТИВНАЯ ИСТИНА, СУДЕБНОЕ ПРОИЗВОДСТВО (РАЗБИРАТЕЛЬСТВО), УГОЛОВНОЕ ДЕЛО

Doi: 10.21515/1990-4665-125-027
UDC 343.1

Legal sciences

\section{PREPARATION OF A PROSECUTOR TO THE REALIZATION OF FUNCTIONS OF ESTABLISHMENT OF OBJECTIVE TRUTH IN A CRIMINAL CASE}

Tushev Alexander Alexandrovich

head of the chair of criminal process, Doctor of Law, professor

Kudin Fyodor Milentyevich professor of the chair of criminal process, Doctor of Law

Tkhakushinov Magomed Aslancherievich professor of the chair of criminal process, Doctor of Law

Teuchezh Asfar Aslanbievich full-time postgraduate of the chair of criminal process

FSBEI HE «Kuban State Agrarian University named after I.T.Trubilin», Krasnodar, Russia

At present time, the authors consider the urgent problem on preparation of a prosecutor to the realization of criminal-procedural function of establishment of objective truth in a criminal case for law enforcement practice. The conclusion on realization of the present function by a prosecutor is substantiated on the basis of directives of a general prosecutor of the RF, a prosecutor of Krasnodar region, the conducted poll of present employers of bodies of a public prosecutor's office of the RF, opinions of scientists in the sphere of process, authors' own arguments and practical recommendations on preparation of its execution are given. The complex analysis of criminal-process authorities of a prosecutor allowing it to achieve the effective establishment of objective truth in a criminal case is carried out

Keywords: PROSECUTOR, CRIMINAL-PROCESS FUNCTION, OBJECTIVE TRUTH, CASE PRODUCTION (TRIAL), CRIMINAL CASE 
Согласно ч. 3 ст. 37 УПК РФ прокурор в ходе судебного разбирательства по уголовному делу поддерживает государственное обвинение, обеспечивая его законность и обоснованность. Несомненно, что государственное обвинение может считаться законным и обоснованным только в том случае, когда сведения об обстоятельствах преступления, установленные в суде, соответствуют обстоятельствам, имевшим место в действительности, установлены в полном и должном объеме, объективно оценены и, что немаловажно, получены в строгом соответствии с требованиями УПК РФ. Иными словами, государственное обвинение, поддерживаемое прокурором в ходе рассмотрения уголовного дела в суде должно основываться на объективной истине.

Генеральный прокурор РФ в п. 1.12. приказа от 27 ноября 2007 года № 189 «Об организации прокурорского надзора за соблюдением конституционных прав граждан в уголовном судопроизводстве» требует от прокуроров постоянно совершенствовать работу по поддержанию государственного обвинения, активно участвовать в судебном следствии, последовательно проверять полноту, всесторонность и объективность собранных в процессе предварительного расследования доказательств, всемерно способствовать установлению судом истины, необходимой для вынесения законного, обоснованного и справедливого приговора [1]. Прокуроры субъектов Российской Федерации во исполнение указаний Генерального прокурора РФ также требуют от прокуроров установления объективной истины по уголовному делу в суде. Так прокурор Краснодарского края Леонид Геннадьевич Коржинек, выступая на расширенном заседании коллегии прокуратуры края, на котором, помимо прочего, обсуждался вопрос поддержания государственного обвинения по уголовным делам, отметил, что своим участием в судебном заседании прокуроры должны способствовать установлению истины по делу [2]. 
Этого мнения придерживаются и многие ученые юристы. Так С. А. Щемеров отмечает, что «Прокурор обязан стремиться к достижению объективной истины. Это вытекает из его правового положения как органа надзора за законностью. Для прокурора осуществление уголовного преследования в форме поддержания государственного обвинения путем реализации принадлежащих ему процессуальных прав является одновременно и выполнение им своих должностных обязанностей, а также нравственного долга по установлению истины» [3]. Высказывая аналогичное мнение, К. А. Бабин отмечает, что «Государственный обвинитель играет решающую роль в установлении объективной истины по делу. Процессуальная форма деятельности государственного обвинителя в суде призвана законодательным путем обеспечить достижение прокурором этой цели. Государственный обвинитель обязан использовать весь арсенал средств доказывания, предусмотренных уголовно-процессуальным законом, для формирования доказательственной основы, которая позволит суду принять законное, обоснованное и справедливое решение по уголовному делу [4].

C учетом того, что уголовное судопроизводство России осуществляется на основе состязательности сторон, можно сделать вывод, что основная тяжесть по установлению объективной истины в суде легла именно на прокурора, т. к. сторона защиты не всегда заинтересована в установлении объективной истины по уголовному делу[5].

Разделяют позицию об осуществлении прокурором уголовнопроцессуальной функции установления объективной истины по уголовному делу в суде и проанкетированные нами в 2016 году прокуроры субъектов Южного и Северо-Кавказского Федеральных округов Российской Федерации, имеющие опыт личного участия в поддержании государственного обвинения в суде. Так $81,1 \%$ опрошенных прокуроров 
указали, что прокурор реализует такую функцию в ходе судебного производства.

Однако не все согласны с необходимостью установления объективной истины по уголовному в суде. Ими высказывается мнение о достаточности установления юридической (процессуальной, судебной) истины. Например, А. В. Аверин полагает, что судья познает не объективную, а юридическую реальность [6]. Но далеко не все практические работники разделяют такую позицию. Всего лишь 4, 9\% опрошенных прокуроров согласны с тем, что по уголовному делу достаточно установить юридическую истину.

Мы также полагаем, что по уголовному делу должна устанавливаться объективная истина.

Как представляется, под объективной истиной, устанавливаемой в судебном разбирательстве, следует понимать соответствие процессуальных выводов и решений суда, отраженных им в приговоре или постановлении о прекращении уголовного дела, событиям, произошедшим в действительности, на основе всестороннего, полного и объективного исследования обстоятельств, подлежащих установлению по уголовному делу.

Для активного и успешного участия в установлении объективной истины судом прокурор должен основательно и тщательно подготовиться. Правильно, на наш взгляд, раскрывает содержание подготовки К. А. Корсаков, который под ней понимает необходимую, обусловленную общими положениями права, особенностями рассматриваемого уголовного дела, личностными качествами лиц, вовлеченных в судопроизводство по делу, и условиями его рассмотрения, сложную систему познавательноаналитической и организационной деятельности, направленной на создание оптимальных условий установления истины и достижения целей уголовного судопроизводства[7]. 
Качество подготовки к поддержанию государственного обвинения зависит от добросовестного подхода прокурора к изучению материалов уголовного дела, всестороннего, полного и объективного исследования содержащейся в них информации о произошедшем событии. В Приказе Генерального прокурора РФ от 25 декабря 2012 года № 465 «Об участии прокуроров в судебных стадиях уголовного судопроизводства» содержится директива руководителям прокуратур о назначении государственных обвинителей заблаговременно, чтобы они имели реальную возможность подготовиться к судебному разбирательству (п. 4.) [8]. Также Генеральный прокурор РФ, учитывая, что процесс познания объективной истины по делу начинается еще на этапе предварительного слушания (если оно проводится), в котором участвует прокурор, и с целью установления объективной истины могут быть заявлены и разрешены ходатайства об исключении доказательств, об истребовании дополнительных, о возвращении дела прокурору, о прекращении уголовного дела или уголовного преследования и т.д., в своем приказеобязывает подчиненных прокуроров уделять должное внимание подготовке к участию на этом этапе уголовного судопроизводства (п. 4.2.Приказа № 465).

Стоит отметить положительный опыт прокуратуры Краснодарского края в этом плане. Так Н. В. Букша отмечает, что в районах Краснодарского края сложилась устойчивая практика заблаговременного назначения государственных обвинителей и своевременного изучения ими уголовных дел, чтобы до рассмотрения дела в суде разрешить все возникающие вопросы, связанные с поддержанием государственного обвинения, в том числе квалификации преступлений и доказанности вины лиц, привлеченных к уголовной ответственности [9].

Однако такая практика налажена не везде. К. А. Корсаков отмечает, что «Как показывает практика, многие прокуроры не уделяют должного внимания подготовке к участию в судебном разбирательстве в качестве 
государственного обвинителя. Это происходит, в основном, по двум причинам: 1 - из-за большой загруженности (у прокурора просто нет времени ознакомиться с материалами уголовного дела, и приходится довольствоваться материалами надзорного производства); 2 - из-за недоцценки значения этой стадии, считая, что в материалах надзорного производства вполне достаточно информации, чтобы успешно решить задачи, вытекающие из функций участвующего в судебном разбирательстве прокурора» [10].

Справедливо полагает Г. И. Налимов, что «... за аксиому... принять одно требование: прокурор, готовящийся к процессу, не может, не имеет права появляться в суде, если он не знает материалов уголовного дела до мелочей: какие данные есть по тому или иному вопросу, где они находятся и в какой форме представлены» [11]. Только качественная и эффективная подготовка к судебному разбирательству, доскональное знание обстоятельств дела, отраженных в его материалах, продуманная тактика поддержания обвинения, позволит прокурору обеспечить всесторонность, полноту и объективность исследования произошедшего события и установить объективную истину по уголовному делу.

На практике используются два наиболее оптимальных тактических приема изучения материалов уголовного дела. Первый способ хронологический порядок изучения материалов уголовно дела, т. е. материалы, прокурором изучаются в том порядке, в каком они расположены в уголовном деле, начиная с постановления о возбуждении уголовного дела. Завершается данный порядок изучением обвинительного заключения (акта, постановления). Второй способ - системный порядок изучения материалов дела, т. е. сначала изучается обвинительное заключение (акт, постановление), а затем материалы уголовно дела.

Большинство процессуалистов указывают на то, что прокуроры предпочитают второй способ изучения, так как начиная изучать материалы 
дела с обвинительного заключения (акта, постановления), они намного быстрее входят в суть дела, более четко уясняют объем обвинения и объем доказательственного материала, существо показаний свидетелей и выводов экспертиз и т. д [12].

Несмотря на все, с первого взгляда, очевидные плюсы такого способа, он имеет обратную, отрицательную сторону. «... Выбирая указанный порядок, государственный обвинитель вынуждено становится сразу на позицию следователя (принимая его выводы за основу изучения материалов дела). В результате это, несомненно, затрудняет выработку собственного мнения по основным вопросам всесторонности, полноты и объективности исследования всех обстоятельств дела. Значительно труднее будет выявить пробелы и упущения предварительного расследования, а значит, и планировать свою деятельность в суде»[10].

Другое опасение такой способ изучения материалов уголовного дела вызывает в связи с тем, что прокурор после изучения обвинительного заключения (акта, постановления) может исследовать только те доказательства, на которые ссылается следователь (дознаватель) в своем процессуальном решении. Пренебрежение в изучении других доказательств не позволит прокурору обеспечить всесторонность, полноту и объективность дальнейшего рассмотрения уголовного дела в суде, так как в неисследованных материалах дела вполне возможно могут содержаться важные сведения для установления объективной истины по делу.

В этой связи представляется, что первый способ изучения материалов уголовного дела будет более продуктивным и нацеленным на установление объективной истины. Прокурор, не связанный процессуальной позицией и выводами следователя (дознавателя), изучая материалы уголовного дела в хронологическом порядке, определяет соблюдение всесторонности, полноты и объективности исследования 
обстоятельств произошедшего события, правильность направления и хода расследования, самостоятельно формирует свою процессуальную позицию на основе беспристрастной оценки собранных доказательств. Прокурор, подходя к завершающему этапу изучения материалов уголовного дела, изучению обвинительного заключения (акта, постановления) уже может сформировать выводы по делу и предполагаемые процессуальные решения по результатам предварительного расследования.

Не лишним для прокурора будет составление своего макета обвинительного заключения (акта, постановления) по результатам изученных материалов уголовного дела. Сравнивая этот макет, а также письменные или мысленные процессуальные выводы с обвинительным заключением (актом, постановлением) следователя (дознавателя), он может определить соответствие процессуальных выводов и решений следователя (дознавателя) обстоятельствам, отраженным в материалах дела.

При существенном расхождении своей позиции с позицией, выраженной в обвинительном заключении (акте, постановлении), государственному обвинителю необходимо доложить об этом прокурору, поручившему поддерживать обвинение (п. 8.Приказа Генерального прокурора РФ от 25 декабря 2012 г. № 465). При мотивированности и обоснованности заявленных разногласий, прокурор и государственный обвинитель безотлагательно должны принять согласованные меры, обеспечивающие законность и обоснованность государственного обвинения (п. 1.12.Приказа Генерального прокурора РФ от 27 ноября 2007 г. № 189 «Об организации прокурорского надзора за соблюдением конституционных прав граждан в уголовном судопроизводстве»). Согласованными мерами государственного обвинителя и прокурора в таком случае будет определение ими законных и обоснованных оснований, которые необходимо заявить в суде для полного или частичного отказа от 
обвинения, изменения объема обвинения в сторону смягчения, а также для возвращения уголовного дела прокурору по основаниям, предусмотренным ст. 237 УПК РФ.

При отсутствии каких-либо разногласий в позициях прокурор, поддерживающий государственное обвинение, должен оценить имеющиеся в уголовном деле доказательства с целью обнаружения доказательств, которые не отвечают требованиям, предъявляемым УПК РФ, для заявления ходатайства об их исключении. Но с учетом того, что чаще всего такие ходатайства подаются стороной защиты для опровержения или смягчения обвинения, прокурору следует спрогнозировать и подготовиться к таким возможным ходатайствам.

При подготовке к предварительному слушанию на основании изученных материалов уголовного дела прокурору необходимо определить дополнительный круг лиц (например, свидетеля, эксперта, специалиста и т. д.), дополнительный перечень доказательств, способных оказать содействие в установлении истины по делу, о вызове или истребовании которых он будет ходатайствовать перед судом.

При подготовке к судебному следствию для установления объективной истины по делу, прокурор должен подготовить речь своего выступления, которой он откроет судебное следствие и изложит существо предъявленного подсудимому обвинения (ч. 1 ст. 273 УПК РФ); определить порядок (очередность) исследования доказательств обвинения (ч. 1 ст. 274 УПК РФ); подготовиться к производству судебных действий и определить тактику своего участия в них (осмотра местности или помещения, следственного эксперимента, освидетельствования и т. д.); также определить тактику исследования как доказательств обвинения, так и доказательств защиты (допрос подсудимого, потерпевшего, свидетеля, эксперта, осмотра вещественных доказательств и т. д.); наметить протоколы следственных действий, заключений эксперта и иных 
документов, имеющих значение для уголовного дела, об оглашении которых в зале судебного заседания он будет ходатайствовать (ст. 285 УПК РФ); подготовить ходатайства об оглашении показаний подсудимого, потерпевшего, свидетеля и воспроизведении приложенных к протоколу допроса материалов фотографирования, аудио- и (или) видеозаписи, киносъемки их показаний (ст. 276, 281 УПК РФ).

После основательной и тщательной подготовки к судебному разбирательству прокурор переходит к реализации уголовнопроцессуальной функции установления объективной истины по уголовному делу в судебных стадиях.

\section{Список литературы}

1. Об организации прокурорского надзора за соблюдением конституционных прав граждан в уголовном судопроизводстве: приказ Генеральной прокуратуры Российской Федерации от 27 ноября 2007 г. № 189 // СПС «КонсультантПлюс».

2. На коллегии прокуратуры Краснодарского края обсуждены вопросы прокурорского надзора за процессуальной деятельностью органов дознания и поддержания государственного обвинения [Электронный ресурс]. - Режим доступа: http://prokuratura-krasnodar.ru/news/na-kollegii-prokuratury-krasnodarskogo-krayaobsuzhdeny-voprosy-prokurorskogo-nadzora-za.

3. Щемеров С.А. Участие прокурора в стадии судебного разбирательства уголовного процесса: автореф. дис. ... канд. юрид. наук. - Нижний Новгород, 2007. - С. 18.

4. Бабин К.А. Уголовное преследование как функция прокурора в уголовном процессе: дис. ... канд. юрид. наук [Электронный ресурс]. - Нижний Новгород, 2008. - Режим доступа: http://www.dissercat.com/content/ugolovnoepresledovanie-kak-funktsiya-prokurora-v-ugolovnom-protsesse-rossii.

5. Тушев А.А. Прокурор в уголовном процессе Российской Федерации. - СПб.: Изд-во Р. Асланова «Юридический центр Пресс», 2005. - С. 234.

6. Аверин А.В. Истина и судебная достоверность (постановка проблемы). - СПб.: Юридический центр Пресс, 2007. - С. 128-129.

7. Корсаков К.А. Криминалистические и процессуальные проблемы подготовки прокурора к судебному разбирательству уголовного дела: автореф. дис. ... канд. юрид. наук. - СПб., 2000. - С. 9.

8. Об участии прокуроров в судебных стадиях уголовного судопроизводства: приказ Генеральной прокуратуры РФ от 25 декабря 2012 г. № 465 // СПС «КонсультантПлюс».

9. Букша Н.В Назначение института прекращения уголовного дела и уголовного преследования: дис. ... канд. юрид. наук. - Краснодар, 2005. - С. 155. 
10. Корсаков К.А. Задачи подготовки прокурора к участию в судебном разбирательстве по уголовным делам [Электронный ресурс] // Интернет-журнал Ассоциации юристов Приморья «Закон». - Режим доступа: http://law.vl.ru/analit/show_m.php.

11. Налимов Г.И. Подготовка государственного обвинителя к участию в судебном разбирательстве // Вестник Пермского университета. Юридические науки. 2007. - № 8. - С. 181-182.

12. Кириллова Н.П. Поддержание государственного обвинения в суде. - Спб., 2003. - C. 46.

\section{References}

1. Ob organizacii prokurorskogo nadzora za sobljudeniem konstitucionnyh prav grazhdan v ugolovnom sudoproizvodstve: prikaz General'noj prokuratury Rossijskoj Federacii ot 27 nojabrja 2007 g. № 189 // SPS «Konsul'tantPljus».

2. $\quad \mathrm{Na}$ kollegii prokuratury Krasnodarskogo kraja obsuzhdeny voprosy prokurorskogo nadzora za processual'noj dejatel'nost'ju organov doznanija i podderzhanija gosudarstvennogo obvinenija [Jelektronnyj resurs]. - Rezhim dostupa: http://prokuraturakrasnodar.ru/news/na-kollegii-prokuratury-krasnodarskogo-kraya-obsuzhdeny-voprosyprokurorskogo-nadzora-za.

3. Shhemerov S.A. Uchastie prokurora $\mathrm{v}$ stadii sudebnogo razbiratel'stva ugolovnogo processa: avtoref. dis. ... kand. jurid. nauk. - Nizhnij Novgorod, 2007. - S. 18.

4. Babin K.A. Ugolovnoe presledovanie kak funkcija prokurora $\mathrm{v}$ ugolovnom processe: dis. ... kand. jurid. nauk [Jelektronnyj resurs]. - Nizhnij Novgorod, 2008. - Rezhim dostupa: http://www.dissercat.com/content/ugolovnoe-presledovanie-kak-funktsiyaprokurora-v-ugolovnom-protsesse-rossii.

5. Tushev A.A. Prokuror v ugolovnom processe Rossijskoj Federacii. - SPb.: Izdvo R. Aslanova «Juridicheskij centr Press», 2005. - S. 234.

6. Averin A.V. Istina i sudebnaja dostovernost' (postanovka problemy). - SPb.: Juridicheskij centr Press, 2007. - S. 128-129.

7. Korsakov K.A. Kriminalisticheskie i processual'nye problemy podgotovki prokurora k sudebnomu razbiratel'stvu ugolovnogo dela: avtoref. dis. ... kand. jurid. nauk. SPb., 2000. - S. 9.

8. Ob uchastii prokurorov $\mathrm{v}$ sudebnyh stadijah ugolovnogo sudoproizvodstva: prikaz General'noj prokuratury RF ot 25 dekabrja 2012 g. № 465 // SPS «Konsul'tantPljus».

9. Buksha N.V Naznachenie instituta prekrashhenija ugolovnogo dela i ugolovnogo presledovanija: dis. ... kand. jurid. nauk. - Krasnodar, 2005. - S. 155.

10. Korsakov K.A. Zadachi podgotovki prokurora $\mathrm{k}$ uchastiju $\mathrm{v}$ sudebnom razbiratel'stve po ugolovnym delam [Jelektronnyj resurs] // Internet-zhurnal Associacii juristov Primor'ja «Zakon». - Rezhim dostupa: http://law.vl.ru/analit/show_m.php.

11. Nalimov G.I. Podgotovka gosudarstvennogo obvinitelja $k$ uchastiju v sudebnom razbiratel'stve // Vestnik Permskogo universiteta. Juridicheskie nauki. - 2007. - № 8. - S. 181-182.

12. Kirillova N.P. Podderzhanie gosudarstvennogo obvinenija v sude. - Spb., 2003. - S. 46. 